\title{
NISHA: Novel Interface for Smart Home Applications for Arabic Regionsubtitle as Needed
}

\author{
Muneer Bani Yassein* \\ Computer Science department \\ Jordan University of Science and Technology \\ Irbid - Jordan
}

\author{
Yaser Khamayseh, Maryan Yatim \\ Computer Science Department \\ Jordan University of Science and Technology \\ Irbid - Jordan
}

\begin{abstract}
Researchers have developed many devices and applications for smart homes to control home's appliances. The main goal of this research is to propose a touch-based interface (namely, NISHA) for smart homes to meet user needs and requirements and is able to control any appliance in the house. This study is designed for people and circumstances in the Middle East countries (Jordan and West Bank) and therefore, is set out to design a user interface for smart home applications taking into consideration the economic, social, and technological differences. Referring to those differences, NISHA was designed in a classical representational design instead of a modern advanced one, based on virtual images instead of text, full control instead of automatic control, and very restrictive privacy issues for people of these countries still look at smart homes as a technology that threaten their privacy. Moreover, NISHA was tested and evaluated using heuristic and cognitive walk-through evaluation techniques. Evaluation results showed that $80 \%$ of users and experts were satisfied with NISHA as a user friendly interface, $90 \%$ of users were satisfied that NISHA met their expectations, and finally, $93 \%$ of users strongly asked to have NISHA in their daily lives.
\end{abstract}

Keywords-Human Computer Interaction (HCI); HCI Design and evaluation methods; User Interface Design; User Centered Design; Smart Homes

\section{INTRODUCTION}

People used to interact, control, and monitor smart homes using web based interfaces, however touch-enabled interfaces overshadowed the web based ones in the last few years, and the challenges remain on how to design better interfaces for controlling the appliances of smart homes. Many user interfaces nowadays are poorly usable. This research is concerned with the improvement of user interface design as a final product. There are plenty of methods on how to design a user interface, but only few of them concentrate on the overall design process. In this work, the design process is covered entirely from early user analysis, such as questionnaires and interviews to implementing or prototyping the actual product. Some limitations such as money, time, and people are taken into consideration while designing the interface. Although there are many HCI rules that should be included in any user interface design like safety, reliability, accessibility, consistency, etc., functionality and usability remain the most important terms that should be considered when implementing, designing, or evaluating any HCI application [18]. The functionality of any system defines the set of services this system can afford. Usability of the system defines how much the user can use the system efficiently and achieve the needed goals of the developed system. However, a system is said to be working effectively if there is a good balance between functionality and usability [5].

To achieve the goals of this study, a plan was first drawn to the design of the interface and methods of achieving the required goals were chosen. First of all, an initial closed ended questionnaire and open ended questions of interviews were performed for a test group of 41 users and 5 experts, and were performed to highlight the vital elements for users' and their goals. Also, expectations of users for extra services and features are identified. A list of interface requirements that should meet the users' needs efficiently was drawn, based not only on HCI rules, but also on the statistics and features analysis of questionnaires and feedback of the test group. Moreover, two evaluation techniques were used for the evaluation of NISHA; heuristic evaluation and cognitive walkthrough. Finally, a prototype was built and connected to the interface so to have a full smart home system that can run in real life scenarios.

\section{A. Interacting with Computing}

Human Computer Interaction (HCI) is defined as a study field of interaction between people and devices; how they use, implement, design, affect, and be affected by computer systems [13]. In the past, developers' main concern was to program a code that works, and they never cared much about users and their needs. Nowadays, with the fast development of smart devices and with the variety of products in the market, the main concern remained on how to deliver a product that satisfies users' needs and requirements. Therefore "User Centered Design UCD is an approach that is centered on determining the context of users and their requirements" [7].

Engineers and designers should have background knowledge of HCI rules so to design better interfaces that can achieve better user satisfaction. This knowledge can be achieved either by literature or by the designers' experience of interface design. Understanding what should be happening when a user is confronted with the interface is not an easy thing. Users want to achieve their goals easily, quickly, and their way. Therefore, designers should have experience and skills that would enhance their final design of the interface. However, it is not enough for designers to rely only on literature as it has limited knowledge. For a better User Interface design, personal experiences and explicit knowledge are essential. Design patterns can also be used as a way to 
capture interface design knowledge. These patterns contain a number of generalized solutions to certain problems and designers can use them in practice.

Smart home interfaces, industrial showcases and laboratories are spread all over the world and are available to all users; although some of them may be more optimized than others, there are still some similarities that are shared among these interfaces and smart home systems. User interfaces are used for monitoring and controlling these smart homes, while the decision making of tasks is managed using artificial intelligent middleware software. Regardless of the working team of the project, the aim of smart home project and smart home interfaces is to have a better system functionality, usability, and testing.

The rest of the paper is organized as follows: Section II presnts the evaluation method. Section III presnts the proposed system timeline. Results are presented and discussed in Section IV. Section V and VI concludeds the paper and presnts some future research directions.

\section{Nisha Evaluation Methods}

During the evaluation of NISHA, two types of evaluation were followed; heuristic evaluation and cognitive walkthrough. A test group of 5 experts was involved in NISHA heuristic evaluation; each expert tested NISHA separately than 3 of the experts met together and discussed the usability problems. The reason that not all experts met is that 3 of them are in in Jordan and the others are in the West Bank. However, we didn't take the formal method of collecting reports from users, instead we highlighted their comments and recommendations.

Using a cognitive walk-through, we built a wooden prototype with two lights and one motor and connected these appliances with electricity to consider this prototype as the smart home. Then we connected NISHA interface with the prototype and prepared three real life scenarios for a test group of 5 experts to test. The scenarios included basic tasks and special tasks and are described in details in section 4.3. Moreover, the results of this method are shown in Tables 2 and 3.

Furthermore, five interviews were made by experts in engineering and development field, the interviewees were asked to highlight the desired design and characteristics of such an interface that will make it meet the HCI rules and user needs.

\section{A. Iterative Strategy}

In this work, three iterations of UCD phases are processed to have better and approximate results according to users. The reason upon why we chose to follow an iterative strategy of UCD phases is that many features and results are not clear from the first process, and only become obvious when first phase results are analyzed. For example, some features might not become clear and certain until users have the prototype to evaluate and revise their needs.

The first iteration of NISHA revealed that it has some weaknesses; experts complained that there is no administration page for administrators to add/remove important buttons, and since any house can have more or less rooms, administrators should be able to control these issues and should have a control panel for administration use only. Moreover, the experts recommended to add a "Weather button" in the front page of NISHA so to make it easier for users to check weather forecasts. Later on, these complaints and recommendations were taken into considerations and NISHA was enhanced and entered the second iteration of its design process. In the second iteration, "Weather" button and administration page were added, the interface was built with a touch enabled device, and evaluation of it has been made using the two evaluation techniques; heuristic evaluation and cognitive walk-through. The results of NISHA evaluation in the second iteration show that it does not include a turn-off-ALL button on all pages but only on the front page of the interface, a weakness that took users much more time to complete the basic tasks. Moreover, the "Back" button on each page of NISHA was placed on the right and not on the left as shown in Fig. 1. Users and experts complained that it is familiar for everybody that the "Back" button is placed on the left of any interface and people will get frustrated searching for this button if it was placed anywhere else. However, when specific tasks were given to experts (i.e. to turn on their morning mode), they recommended the interface to have a "Scenario" button in the front page of NISHA so people can finish the task with one click instead of having 3 clicks by doing each action separately. Furthermore, referring back to literature review findings, work in [8] proved that considering images instead of colors when designing buttons achieve more user satisfaction and higher learnability, at this point the solid color buttons of NISHA where replaced with Virtual image buttons as shown in Fig. 2.

After modifying NISHA based on the results of the second iteration, the interface was given again to a test group to evaluate. Third evaluation of NISHA showed better results but also revealed some missing features that should be included in it; when performing the basic tasks, users found it easier if there were a "Cameras" button that allow users to view their house's rooms in camera frames instead of entering each room

TABLE I. Literature REVIEW Findings (STRENGTHS AND WEAKNESSES)

\begin{tabular}{|l|l|l|}
\hline Literature Review & Strengths & Weaknesses / Challenges \\
\hline $\begin{array}{l}\text { Virtual Place Framework for User-centered Smart } \\
\text { Home Applications [9] }\end{array}$ & $\begin{array}{l}\text { Guidelines on how to involve users in the design process to reduce } \\
\text { the gap } \\
\text { Virtual Reality increased accessibility of system }\end{array}$ & Generality of guidelines \\
\hline $\begin{array}{l}\text { Human Centred Design for Graphical User } \\
\text { Interfaces [15] }\end{array}$ & $\begin{array}{l}\text { Guidelines } \\
\text { Images instead of colors } \\
\text { Use color contrasts to separate }\end{array}$ & Usability Centered Only \\
\hline
\end{tabular}




\begin{tabular}{|c|c|c|}
\hline & $\begin{array}{l}\text { Contrasts are very effective } \\
\text { Consider color blind people }\end{array}$ & \\
\hline $\begin{array}{l}\text { Design and evaluation of smart home user } \\
\text { interface: effects of age, tasks and intelligence } \\
\text { level [2] }\end{array}$ & Less time and Less errors using guidelines presented & $\begin{array}{l}\text { Performance not clearly } \\
\text { differentiated for senior people vs. } \\
\text { young people }\end{array}$ \\
\hline $\begin{array}{l}\text { Smart Home, the Next Generation Closing the Gap } \\
\text { between Users and Technology [1] }\end{array}$ & $\begin{array}{l}\text { Full control over interaction by user achieved better results of } \\
\text { usability }\end{array}$ & $\begin{array}{l}\text { Problems with accessibility } \\
\text { No predefined sets of guidelines }\end{array}$ \\
\hline $\begin{array}{l}\text { Design of web-based Smart Home with 3D virtural } \\
\text { reality interface [16] }\end{array}$ & $\begin{array}{l}\text { 3D presentation of devices provides great convenience, flexibility, } \\
\text { and immersive visualization to users }\end{array}$ & $\begin{array}{l}\text { High complexity because of costs of } \\
\text { much more software design and } \\
\text { hardware's }\end{array}$ \\
\hline $\begin{array}{l}\text { Projection-Based User Interface for Smart Home } \\
\text { Environments [4] }\end{array}$ & $\begin{array}{l}\text { Very feasible approach } \\
\text { More intuitive and natural way of user interaction because touch } \\
\text { based } \\
\text { Gesture recognition model for fingertips mapping }\end{array}$ & High response time \\
\hline $\begin{array}{l}\text { HouseGenie: Universal Monitor and Controller of } \\
\text { Networked Devices on Touchscreen Phone in } \\
\text { Smart Home [17] }\end{array}$ & $\begin{array}{l}\text { Avoided confusion of too many devices in small screen display by } \\
\text { adopting the filtered mode so users can focus on the important } \\
\text { icons and hide unneeded ones }\end{array}$ & $\begin{array}{l}\text { Not Pleasure to use - } 2 \mathrm{D} \text { panoramic } \\
\text { two layered view }\end{array}$ \\
\hline $\begin{array}{l}\text { Control Your Smart Home with an Autonomously } \\
\text { Mobile Smartphone [7] }\end{array}$ & Combination of voice and touch & Voice recognition Problems \\
\hline 3D virtual "smart home" user interface [3] & Virtual Reality technology & $\begin{array}{l}\text { Users preferred cameras instead of } \\
\text { the presented 3D interface }\end{array}$ \\
\hline $\begin{array}{l}\text { Design of a touch screen interface for a mobile } \\
\text { position aware instant messaging client [6] }\end{array}$ & Low response time & $\begin{array}{l}\text { Assumption of one hand not } \\
\text { convenient } \\
\text { Didn't involve users and hence user } \\
\text { satisfaction was low }\end{array}$ \\
\hline
\end{tabular}

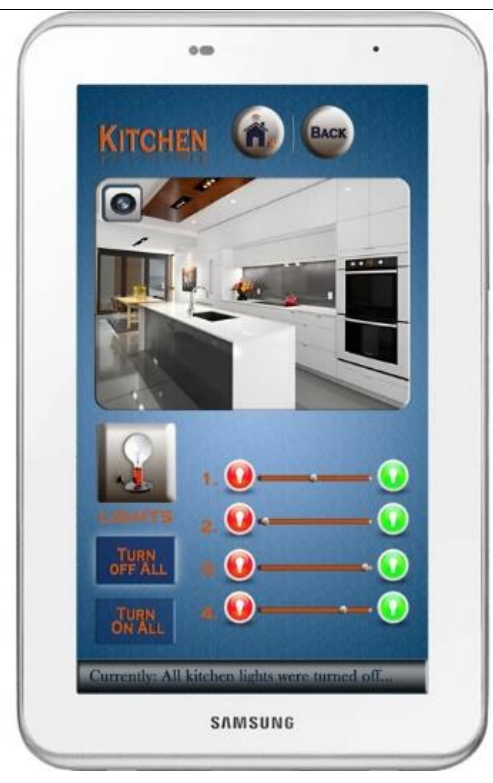

Fig. 1. "Back" button placed on the right of the page - weakness 


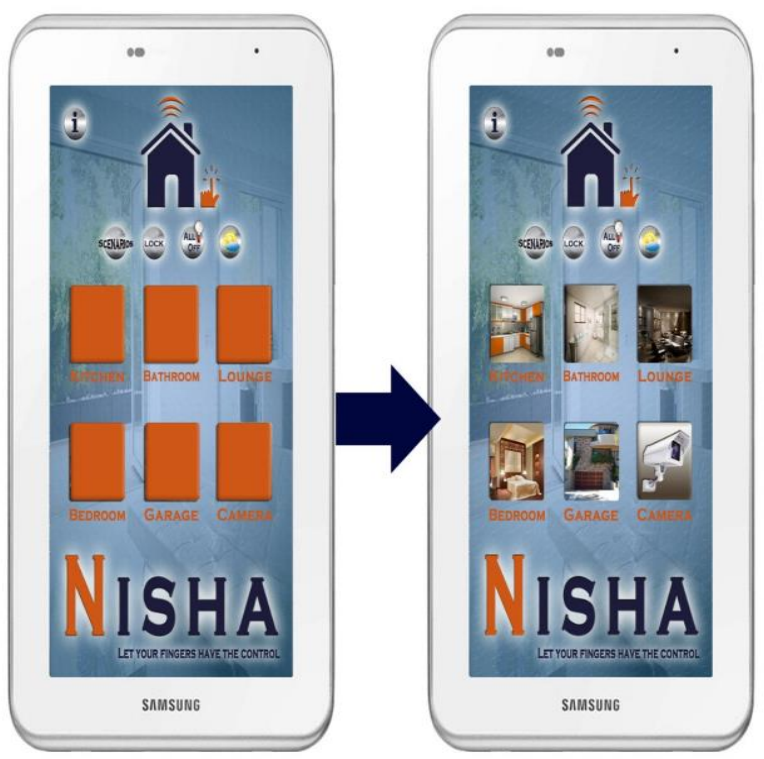

Fig. 2. Virtual images buttons instead of solid colour buttons

TABLE II. NISHA VALUES FOR THE MEASUREMENT OF “TASK TIME" / TIME IN SECONDS

\begin{tabular}{|l|l|l|l|}
\hline Iteration & Basic Tasks & Special Tasks & Avg. Total Task Time \\
\hline 1 & 41.4 & 37.2 & 39.3 \\
\hline 2 & 32 & 37.2 & 34.6 \\
\hline 3 & 26.7 & 28.5 & 27.6 \\
\hline
\end{tabular}

TABLE III. Nisha VALUES FOR USABILITY PARAMETERS CONSIDERED

\begin{tabular}{|l|l|l|l|l|l|}
\hline Iteration & Satisfaction & $\begin{array}{c}\text { Avg. No. } \\
\text { of Clicks }\end{array}$ & $\begin{array}{c}\text { Avg. } \\
\text { Time } \\
\text { asking } \\
\text { for }\end{array}$ & $\begin{array}{c}\text { Avg. } \\
\text { No. of } \\
\text { user } \\
\text { lost }\end{array}$ & $\begin{array}{c}\text { Avg. No. } \\
\text { a user } \\
\text { got } \\
\text { frustrated }\end{array}$ \\
\hline 1 & 1.92 & 4 & 10.2 & 2.7 & 2.7 \\
\hline 2 & 1.78 & 3 & 6.6 & 1.2 & 1.2 \\
\hline 3 & 1.54 & 3 & 2.5 & 0 & 0.4 \\
\hline
\end{tabular}

Separately to view the camera frame. Also, experts complained that a "Recent Actions" page is missing and stated that people find it very important to check such a page so to make sure of the actions they have done recently. These two issues were compared to the $\mathrm{HCI}$ intersection model drawn at the research phase of the first iteration, and found that they are concerned with Learnability and Flexibility aspects. Finally, the third iteration of NISHA has been made based on the third evaluation and again given for users and experts to evaluate.

After modifying NISHA based on the results of the second iteration, the interface was given again to a test group to evaluate. Third evaluation of NISHA showed better results but also revealed some missing features that should be included in it; when performing the basic tasks, users found it easier if there were a "Cameras" button that allow users to view their house's rooms in camera frames instead of entering each room separately to view the camera frame. Also, experts complained that a "Recent Actions" page is missing and stated that people find it very important to check such a page so to make sure of the actions they have done recently. These two issues were compared to the HCI intersection model drawn at the research phase of the first iteration, and found that they are concerned with Learnability and Flexibility aspects. Finally, the third iteration of NISHA has been made based on the third evaluation and again given for users and experts to evaluate. The fourth evaluation of NISHA was promising and showed better results compared to the first and second iteration, NISHA also achieved positive experts' and users' comments.

\section{B. Pre-Questionnaire Structure}

The following topics were contained in the prequestionnaire:

- General questions: Age, gender, and professional status.

- Requirement questions

- Interface features

- Special features questions

Furthermore, in the experts' interviews additional questions were asked to the experts about new or recommended ideas for the application. Most of the questions in the interviews were open. Some of those questions are:

- What are the buttons the users use most?

- How often do users ask for help?

- Is there any features users ask for, that are not found in the existing interfaces? Kindly provide us with examples.

\section{Methodology Timeline}

Fig. 1. NISHA designing process timeline presents the timeline of NISHA designing, development, and evaluation phases. First of all, huge research have been made on existing similar interfaces and on smart home implementation, then strengths and weaknesses of these interfaces and works have been taken into consideration and used to build a background knowledge and identify potential problems. Secondly, an online closed ended pre-questionnaire was conducted and given to a test group of 41 typical users to fill in order to have w background knowledge of these users and their mentality. The pre-questionnaire questions were chosen based on the experts' recommended features and on Nielsen's standards of usability [11]. At the point everything have become clear to draw an initial design of the interface, so mockups were made for NISHA based on the intersection and on the results of the pre-questionnaire.

At the testing design phase, the mock-ups were tested by the same experts and compared to the HCI rules chosen first and to the users' requirements collected from the prequestionnaire. Moreover, at this phase, the mockups were tested by some of the usability aspects like learnability, flexibility, and robustness. Testing Design phase is iteratively repeated during the development cycle of NISHA until the initial design of the interface met users' requirements and $\mathrm{HCI}$ rules that were listed in the third phase. Later on, the real design of NISHA was made on a touch enabled device and linked to a wooden house-prototype that has two lights and one motor connected to the electricity. 


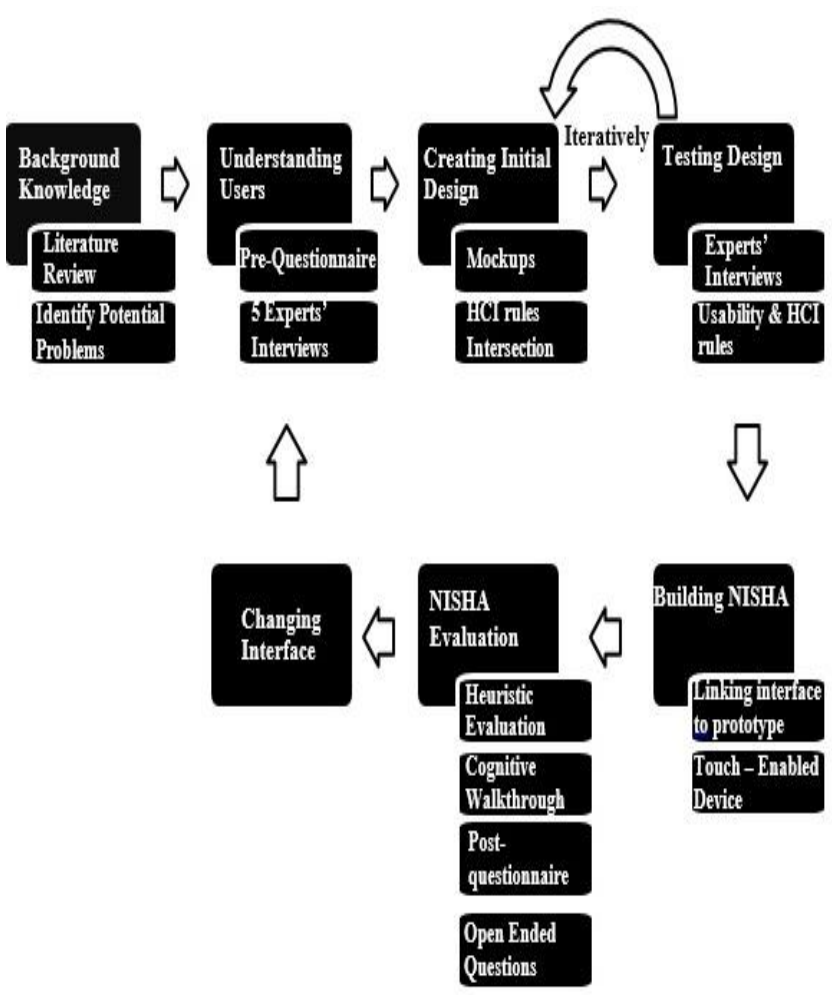

Fig. 3. NISHA designing process timeline

In the Evaluation level of NISHA two types of evaluation methods were considered; heuristic evaluation and cognitive walkthrough. In heuristic evaluation method another test group of 10 users were prepared to test NISHA as a user interface only without the use of a prototype only by providing these users with simple tasks to perform. The tasks given to the test group were mainly concerned to highlight interface features' issues such as consistency of pages, simplicity of use, and learnability of system, and did not consider other issues like response time and push up notifications because at this evaluation phase, the interface was not connected to the wooden prototype. On the other hand, we used cognitive walkthrough evaluation method by preparing 3 lifetime scenarios and given these scenarios to the same experts test group of the third phase to perform them. Each expert have been given NISHA on a touch-based device and was asked to perform certain tasks. Then, experts were asked to list the most negative and positive aspects of the interface and were asked an open ended questions like "how do you think NISHA can help you in your daily life?" Furthermore, number of clicks, time to finish a certain task, and users' reactions were recorded to evaluate NISHA. Finally, based on the interface evaluation, NISHA was enhanced and changed.

\section{RESULTS}

\section{A. Pre-Questionnaire}

The main goal of the online pre-questionnaire is to highlight the cultural, economic, social, and technological differences for people in the Arab Countries (Jordan and the West Bank). Since the circumstances and situations in the Arab world differ from other countries (ex. 3G technology is not available in the West Bank and hence users don't always have control over their homes), it is very important to build a background knowledge of these factors before designing such an interface.

\section{B. Interface Post-Questionnaires}

Another test group of 10 users were prepared to test NISHA as a user interface only, without the use of a prototype by providing these users with simple tasks to perform. The tasks given to the test group were mainly concerned to highlight interface features' issues such as consistency of pages, simplicity of use, and learnability of system, and did not consider other issues like response time and push up notifications because at this evaluation phase, the interface was not connected to the wooden prototype and hence there was no full system yet. The test group filled in an online questionnaire and results were satisfying; $100 \%$ of users agreed that the interface does not contain a lot of information on the screen, 90\% agreed that the content fits well within the display and that information on the same screen is relevant, $20 \%$ found it misleading while $80 \%$ did not, $70 \%$ was able to use the interface with one hand, $60 \%$ agreed that there is no need to include narratives since interface is clear, $40 \%$ used a minimal number of click to reach their goal, 20\% used the perfect number of clicks, and $30 \%$ stated that the number of clicks is normal. Also, $90 \%$ agreed that the interface ensure consistency while navigating from one screen to another and switching between screens, and $80 \%$ found it easy to diagnose and recover from errors.

When given a certain tasks to perform, $40 \%$ found the tasks neither difficult nor easy, $40 \%$ found them difficult, $10 \%$ only thought the tasks are easy. After completing the tasks, $40 \%$ stated that the tasks are very easy, $30 \%$ voted for "somewhat easy" option, and $10 \%$ only found the tasks difficult. There was a consensus of users that the characters on the screen are easy to read, $80 \%$ stated that they would recommend it to their friends and colleagues. Finally 50\% strongly agreed to use the system frequently and $40 \%$ agreed to use it frequently.

\section{Prototype Evaluation}

To evaluate the developed interface based on real time actions, three scenarios have been prepared for a test group of the same experts of the interviews. Each expert have been given NISHA on a touch-based device and was asked to perform certain tasks that connect the interface with the built prototype. The prototype is a $1 \mathrm{x} 1$ meter wooden built house, with two lights and one motor. Users' reactions and comments were recorded while performing the tasks, and also they were asked to fill in the post-questionnaire after completing the tasks. The three scenarios given to experts are described as follows:

\section{1) Scenario 1}

Description: it is very desirable for users when leaving their house to switch off/on ALL the devices, for sure except those that always have to be turned on like the alarm system, refrigerator, etc. NISHA should be able to handle this and allow users to turn off/on these appliances before leaving or entering the house. This feature is one of the most important features that users asked for in the pre-questionnaire. 


\section{a) Scenario 1 - Task 1}

After a long working day, it's time to have some rest and sleep. Unfortunately, while you are sleeping late at night, you hear footsteps and a strange movement around in your kitchen. You are very sleepy and still can't recognize whether it's an illusion or a real danger. The best thing to do is to turn on ALL of your kitchen's lights so everything becomes clear, but apparently it is a bad idea to risk and walk in the dark to turn on the lights. Moreover, if everything is ok, then it is time to turn off ALL unneeded appliances and lights in the house and sleep. How can you handle this problem using NISHA?

2) Scenario 2

Description: any appliance in the house can be switched on/off remotely from the application NISHA. A notification is shown to the users if any device is switched on/off or had a change in its current status.

\section{a) Scenario 2 - Task2}

Its morning, and you left your house heading to work, while driving you turn on the radio and the weather forecast predicts that a strong storm is coming at night. You remember that you left all your kitchen windows opened, and unfortunately you have a long working day and will not be back until very late. Use your NISHA to handle this problem.

3) Scenario 3

Description: Beside that smart home applications should be able to turn on/off ALL lights, any appliance or light in the house can be controlled separately by users.

\section{a) Scenario 3 - Task3}

On a Sunday morning you wake up with a fresh mind and a relaxed body, but absolutely you will stay in bed as long as your windows are closed and as long as your coffee is not ready, apparently this is you morning mode. How could you enjoy the morning mode without the need of leaving your bed? Also you need to turn on ONLY one of your kitchen lights so to be able to see the coffee machine on the camera.

User comments and reactions were recorded, and they were asked to answer some questions. The results of this evaluation is summarized in Table 4, Table 5, and Table 6.

\section{CONCLUSION}

This paper addressed the problem of inadequate usability of existing user interfaces for controlling home devices. Previous and existing user interfaces for controlling smart homes were promising, but were not usable and useful enough to meet users' expectations for a user friendly and "good" smart home interfaces. This led to the idea of designing a touch-based user interface for smart home systems that meets user expectations and follow as much as possible Human Computer Interaction rules. This study examined people, and circumstances of the developing countries of Middle East (Jordan and West Bank) and therefore is set out to design a user interface for smart home systems taking into consideration the economic, social, cultural, and technological differences that occur between these countries and other developed countries. This study included three stages; at first - in a preliminary study - users' expectations and needs were collected through an online prequestionnaire and experts' interviews, resulting in an initial list of users' requirements; secondly, initial design of the interface was developed and given for typical users to evaluate through an online post-questionnaire, 3 iterations of interface design were then made;

Finally, the final design of NISHA has been developed and given to a number of experts to test. The Preliminary study of users in addition to experts' interviews examined the user interface elements that are highly influenced by economic, social, technological, and cultural values of Jordan and West Bank countries, and revealed that there are many differences that should be taken into consideration when designing a user interface for people in this region; Pre-questionnaire form showed that people preferred classical old fashion interfaces instead of modern advanced ones such as sliding of pages and fading of images. Moreover, experts' interviews revealed that people in these countries have high fear of smart technologies and consider these technologies as a threat to their privacy; hence NISHA was designed in a way that users can put a security key whenever they want to enter the application. Literature review studies also showed that people of the Arab countries in general don't like text-buttons and prefer to see virtual images instead of text [10], therefore NISHA buttons were designed based on virtual images. Moreover, as Blue color is considered to indicate protection in Arab cultures [14], it was considered for NISHA logo and design. Finally, as the $3 \mathrm{G}$ technology is not always available in West Bank countries, and since people don't always have access to the internet, NISHA was designed to be working automatically in special cases, and not to wait for users' confirmation (i.e. if there is a strong storm, close windows without waiting users' confirmation).

The final evaluation of NISHA by experts involved a 3 prepared real life scenarios that were given to those experts as a tasks to be done using the interface over a wooden house prototype that consists of two lights and a motor. Finally, results and feedback of post-questionnaire and experts' evaluation showed that users' and experts' satisfaction of using the interface was high and ranked an average of 8 out of 10 $(80 \%)$ compared to the existing smart home interfaces. Moreover, $90 \%$ of users were satisfied that NISHA met their expectations, and finally $93 \%$ of users strongly asked to have NISHA in their daily lives.

\section{FUTURE WORK}

First of all, as the feedback of users refers to the responsetime of the interface is not very fast, we aim to enhance this feature. Secondly, a combination of touch-speech-recognition interface is planned to be developed since users find it easier for some tasks to be done by voice commands instead of touch commands. This is planned to be done by allowing users to use their voice for general tasks, like entering the kitchen, opening the windows, turning off the lights, etc. While specific tasks like oven settings, scenarios, etc. are controlled by touching commands. 
TABLE IV. NISHA EVALUATION RESULTS BASED ON EXPERTS’ REACTIONS / RECORDING

\begin{tabular}{|c|c|c|}
\hline & $\begin{array}{l}\text { Please list the most positive aspects you found using this } \\
\text { interface }\end{array}$ & $\begin{array}{l}\text { Please list the most negative aspects you faced using this } \\
\text { interface }\end{array}$ \\
\hline Expert 1 & $\begin{array}{l}\text { "Very simple to use" } \\
\text { "User-friendly" } \\
\text { "Clear Buttons" }\end{array}$ & "Not of a very high responding speed" \\
\hline Expert 2 & $\begin{array}{l}\text { "Very simple and usable" } \\
\text { "Contains every single detail the user may ask for" }\end{array}$ & "Presets Page is not clear" \\
\hline Expert 3 & $\begin{array}{l}\text { "It saves my time" } \\
\text { "It is Useful" }\end{array}$ & "Responding time is high" \\
\hline Expert 4 & $\begin{array}{l}\text { "Navigation among screens is easy" } \\
\text { "Very user friendly and simple" }\end{array}$ & "None" \\
\hline Expert 5 & $\begin{array}{l}\text { "This interface is very easy to use and can save my time, I was } \\
\text { pleased while testing and performing the scenarios" }\end{array}$ & "Presentational design is of an old fashion" \\
\hline
\end{tabular}

TABLE V. Nisha EVALUATION RESUlts By EXPERTS / DiRECT Closed ENDED QUESTIONS

\begin{tabular}{|l|l|l|l|l|l|}
\hline & $\begin{array}{l}\text { Strongly } \\
\text { Agree }\end{array}$ & Agree & Disagree & $\begin{array}{l}\text { Strongly } \\
\text { Disagree }\end{array}$ & N/A \\
\hline It makes Things I want to accomplish easier to get done & $20 \%$ & $80 \%$ & - & - & - \\
\hline It saves my time & $60 \%$ & $20 \%$ & - & - & $20 \%$ \\
\hline It is Simple to use & $80 \%$ & $20 \%$ & - & - & - \\
\hline Using this interface is effortless & - & $80 \%$ & - & - & $20 \%$ \\
\hline Shifting among buttons is easy & $40 \%$ & $60 \%$ & - & - & - \\
\hline It has all the functions and capabilities I expect it to have & $60 \%$ & $20 \%$ & $20 \%$ & - & - \\
\hline I feel I need to have it & $60 \%$ & $20 \%$ & $20 \%$ & - & - \\
\hline
\end{tabular}

TABLE VI. Nisha Evaluation Results by EXPERTs / DiReCt Closed ENDED QUESTIONS

\begin{tabular}{|c|c|c|}
\hline & $\begin{array}{l}\text { Please list the most positive aspects you found using this } \\
\text { interface }\end{array}$ & $\begin{array}{l}\text { Please list the most negative aspects you faced using this } \\
\text { interface }\end{array}$ \\
\hline Expert 1 & $\begin{array}{l}\text { "Very simple to use" } \\
\text { "User-friendly", } \\
\text { "Clear Buttons" }\end{array}$ & "Not of a very high responding speed" \\
\hline Expert 2 & $\begin{array}{l}\text { "Very simple and usable" } \\
\text { "Contains every single detail the user may ask for" }\end{array}$ & "Presets Page is not clear" \\
\hline Expert 3 & $\begin{array}{l}\text { "It saves my time" } \\
\text { "It is Useful" }\end{array}$ & "Responding time is high" \\
\hline Expert 4 & $\begin{array}{l}\text { "Navigation among screens is easy" } \\
\text { "Very user friendly and simple" }\end{array}$ & "None" \\
\hline Expert 5 & $\begin{array}{l}\text { "This interface is very easy to use and can save my time, I was } \\
\text { pleased while testing and performing the scenarios" }\end{array}$ & "Presentational design is of an old fashion" \\
\hline
\end{tabular}

[1] HwangA., HoeyJ., Smart Home, The Next Generation Closing the Gap between Users and Technology; [Online] [Accessed on 2014 March]. Available from URL https://cs.uwaterloo.ca/ jhoey/papers/AAAISS2012HwangHoey.pdf.

[2] Bin Z, Pei-Luen PR, Gavriel S, Design and evaluation of smart home user interface: effects of age, tasks and intelligence level; Behaviour \& Information Technology,2009, vol. 28,pp.239-249.

[3] Borodulkin L, Ruser H, Trankler HR, 3D virtual "smart home" user interface. Virtual and Intelligent Measurement Systems; VIMS IEEE International Symposium, 2002,pp.111- 115 .

[4] Chin-Yang Lin, Yi-Bin Lin, Projection-Based User Interface for Smart Home Environments; Computer Software and Applications Conference Workshops (COMPSACW) IEEE 37th Annual; Japan; pp. 546 - 549.

[5] Davis FD, Perceived Usefulness, Perceived Ease of Use, and User Acceptance of Information Technology; MIS Quarterly, 1989, vo. 13,pp.319-340.

[6] StenmarkF., Design of a touch screen interface for a mobile position aware instant messaging client; [Online] [Accessed 2014 April].
[7] WangH., Saboune J, El Saddik A,Control Your Smart Home with an Autonomously Mobile Smartphone; Multimedia and Expo Workshops (ICMEW) IEEE International Conference; San Jose, 2013CA, pp.1-6.

[8] Hwang A., Truong K., Mihailidis A;; Using participatory design to determine the needs of informal caregivers for smart home user interfaces; 6thInternational Conference on Pervasive Computing Technologies for Healthcare (PervasiveHealth); Diego, 2012CA; pp. 41-48.

[9] Jumphon L., Jinwon C.;; Virtual Place Framework for User-centered Smart Home Applications; Mahmoud A. Al-Qutayri; Smart Home Systems.Korea; 2010,pp.177- 193.

[10] Khanum, M. Akheela, F., Shameem, Chaurasia, Mousmi A;; Arabic Interface Analysis Based on Cultural Markers; International Journal of Computer Science,2012vol. 9, no. 1,pp 255-260.

[11] Nielsen, JUsability Engineering. Academic Press, Boston; ISBN 0-12518405-0 (hardcover), 0-12-518406-9 (softcover1993; Japanese translation ISBN 4-8101-9009-9. 
[12] Othmar Kyas, How to Smart Home; [Online] [Accessed 2014 February]; Available from URL http://www.openremote.com/wpcontent/uploads/2013/12/How-To-Smart-Home-PDF-OR.pdf

[13] ZhangP.,BenbasatI., CareyJ., Fred Davis, Dennis F Galletta, Diane M Strong;; Human-Computer Interaction Research in MIS Discipline; AIS Transactions on Human-Computer Interaction; 2002, vol. 3, no. 1,pp. 55-107.

[14] Ruecian, Colors of Religion: Islam; [Online] [Accessed 2014 March]. Available from

URL, http://www.colourlovers.com/blog/2007/09/08/colors-of-religion-islam/

[15] Van der Veer, Human centred Design for Graphical User Interfaces.[Online] [Accessed 2014 May]. Available from URL http://publik.tuwien.ac.at/files/pub-inf_2609.pdf
[16] Wenshan Hu, ZhouH., Chaoyang Lin, ChenX., ChenZ., Yiyan Lu;; Design of web-based Smart Home with 3D Virtural Reality Interface; Control (CONTROL) UKACC International Conference;; 2012,pp. 223 $-228$.

[17] Yue S., Chenjun W., Yongqiang Q., Chun Yu, Yu Zhong, Yuanchun Shi;; HouseGenie: Universal Monitor and Controller of Networked Devices on Touchscreen Phone in Smart Home; Ubiquitous Intelligence \& Computing and 7th International Conference on Autonomic \& Trusted Computing (UIC/ATC); Xian, Shaanxi; 2010,pp.487-489.

[18] KhamaysehY., MardiniW.AljawarnehS., Bani_YasseinM.," Integration of Wireless Technologies in Smart University Campus Environment: Framework Architecture", International Journal of Information and Communication Technology Education, 2015, vol. 11, no. 2, pp.60-74. 